\title{
X-Ray Line Profile Analysis of Chemically Deposited Nanostructured PBS Films
}

\author{
Bhaskarjyoti Baruah $^{1}{ }^{*}$, Lakhi Saikia ${ }^{2}$, Mothura Nath Bora ${ }^{1}$, Kanak Ch. Sarma ${ }^{3}$ \\ ${ }^{1}$ Dept. of Physics, D R College, Golaghat-785621, India \\ ${ }^{2}$ Material Science Division, NEIST, Jorhat-785006, India \\ ${ }^{3}$ Dept. of Instrumentation \& USIC, Gauhati University, Guwahati-781014, India
}

\begin{abstract}
Nanocrystalline films of PbS have been deposited on glass sustrates at room temperature by $C B D$ method. The structural parameters of PbS films have been studied by X-ray line profile analysis using Williamson Hall and Modified Williamson Hall method. The crystallite sizes are found in between 4.99-53.9 nm, strain in the films in the range of $7.4 \times 10^{-4}-2.82 \times 10^{-3}$ and dislocation densities are found to be very high $10^{15}-10^{16} \mathrm{~m}^{-2}$.
\end{abstract}

Keywords: Chemical Bath Deposition, Dislocation density, Dislocation contrast factor, MWH plot, WH plot

\section{Introduction:}

$\mathrm{PbS}$ is a IV-VI semiconductor with a direct bandgap of $0.41 \mathrm{eV}$ (in bulk form) and exciton Bohr radius of $18 \mathrm{~nm}$ [1].It has been attracting wide interest because of its scope of applications in optoelectronics[2-5]. Amongst the various methods available for the synthesis of thin films of PbS, the Chemical Bath Deposition (CBD) method has its relative advantage such as simplicity, cost effetiveness and convenience for large area deposition [6]. Although significant amount of research works have been reported for exploring the optical and electrical properties of nanostructured films of PbS[7-9], only few works have been reported on structural attributes. Most of the works using X-ray line profile analysis of nanocrystalline materials ignore the contbution of strain on broadening. Classical Williamson-Hall (WH) method, generally used for separating strain broadening and size broadening is not suitable in the presence of strain anisotropy[10]. The effect of strain anisotropy has been incorporated in the Modified Williamson Hall (MWH) method[11-14]In the present work, the X-ray diffraction patterns of nanocrystalline $\mathrm{PbS}$ films prepared by CBD method have been analyzed by WH and MWH method and crystallite size, lattice strain and dislocation density are reported.

\section{Experimental details:}

$\mathrm{PbS}$ films were deposited in glass substrates by Chemical Bath Deposition Method. Three solutions of $\mathrm{Pb}\left(\mathrm{CH}_{3} \mathrm{COO}\right)_{2}$ of concentrations $0.50 \mathrm{M}, 0.75 \mathrm{M}$ and $1.00 \mathrm{M}$ were prepared separately in deionized water. To $5 \mathrm{ml}$ of each solution, $5 \mathrm{ml}$ of $2 \mathrm{M} \mathrm{NaOH}$ solution and $2 \mathrm{ml}$ of $1 \mathrm{M}$ triethanolamine(TEA) were added. The $\mathrm{pH}$ became 11. Now to each of the bath solution, $6 \mathrm{ml}$ of $1 \mathrm{M}$ thiourea was added. Within $45 \mathrm{~s}$, the colour of each solution turned dark brown. Properly cleaned glass substrates were vertically immersed into the baths. After $17 \mathrm{hrs}$. of deposition, the substrates were taken out of the bath and thoroughly washed with double distilled water. Then the films were dried in air at room temperature.The films deposited using solutions of $\mathrm{Pb}\left(\mathrm{CH}_{3} \mathrm{COO}\right)_{2}$ of concentrations $0.50 \mathrm{M}, 0.75 \mathrm{M}$ and $1.00 \mathrm{M}$ have been coded as $0.50 \mathrm{M}(\mathrm{LAc}), 0.75 \mathrm{M}$ (LAc) and $1.00 \mathrm{M}$ (LAc) respectively.

The X-ray diffraction pattern of the films were recorded by Rigaku Ultima IV X-ray diffractometer at room temperature with $\mathrm{CuK} \alpha$ radiation having wavelength $1.5406 \AA$.

\subsection{Crystallite size using Scherrer's Formula:}

\section{Determination of Structural Parameters:}

The average crystallite sizes(D) of the nanocrystalline $\mathrm{PbS}$ films are obtained by using Scherrer's equation [15]:

$$
\mathrm{D}=0.94 \lambda / \beta \cos \theta
$$

(1)

where $\lambda$ is the wavelengh of X-ray used, $\beta$ is the fwhm of the peak in radian corresponding to a particular set of crystal plane and $\theta$ is the Bragg angle. This formula gives the average crystallite sizes in a direction perpendicular to the respective planes.

\subsection{Lattice constant from Nelson-Riley plot:}

The lattice constant ' $a$ ' for the cubic phase is given by the relaton:

$$
\mathrm{a}=\mathrm{d}\left(\mathrm{h}^{2}+\mathrm{k}^{2}+\mathrm{l}^{2}\right)^{1 / 2}
$$


where $\mathrm{d}$ is the interplanar spacing of the crystal planes represented by Miller indices (hkl).

The corrected values of 'a' are estimated from the Nelson-Riley plots by plotting the values of 'a' against the error function:

$$
f(\theta)=1 / 2\left(\operatorname{Cos}^{2} \theta / \operatorname{Sin} \theta+\operatorname{Cos}^{2} \theta / \theta\right)
$$

(3)

and extrapolating to $\theta=90^{\circ}[16]$

\subsection{Crystallite size and strain from Williamson-Hall plot:}

The deviation of 'a' from its bulk value $\left(\mathrm{a}_{0}=5.936 \AA\right.$ ) [17] shows that the films are under strain. If the size and strain broadening are present simultaneously, then the crystallite size and strain may be obtained from Williamson- Hall (WH) plot. Assuming both size and strain broadened profile are of similar nature, Williamson and Hall used the following equation [18]:

$$
\Delta \mathrm{K}=\left(0.9 / \mathrm{D}_{\mathrm{wH}}\right)+2 \varepsilon \mathrm{K}
$$

where $\mathrm{K}=2 \sin \theta / \lambda, \Delta \mathrm{K}=\beta \cos \theta / \lambda, \varepsilon$ is the strain and $\mathrm{D}_{\mathrm{WH}}$ is the crystallite size as given by WH plot. A linear plot of $\Delta \mathrm{K}$ vs $\mathrm{K}$ gives

the WH plot whose intercept and slope gives the crystallite size and microstrain respectively, according to eq. (6).

\subsection{Crystallite Size and Dislocation Density from Modified Williamson-Hall plot:}

Assuming dislocations to be the main contributors to strain, the x-ray diffraction data are analyzed by modified Williamson-Hall (MWH) method[10-14 ]. In the MWH method, eq.(6) has been modified to introduce a dislocation contrast factor $\mathbf{C}_{\mathbf{h k l}}$ such that it takes the form[ 10, 13]:

$$
(\Delta \mathrm{K})^{2}=\left(0.9 / \mathrm{D}_{\mathrm{MWH}}\right)^{2}+\left(\pi \mathrm{b}^{2} \rho / 2 \mathrm{~B}\right) \mathrm{K}^{2} \mathrm{C}_{\mathrm{hkl}}
$$

where $\mathrm{D}_{\mathrm{MWH}}$ is the average crystallite size, $\rho$ is the average dislocation density, $\mathrm{b}=\mathrm{a} / \sqrt{2}$ (for fcc crystal) is the modulus of Berger's vector of dislocation, B is a constant that can be taken as 10 [13].

For an untexured polycrystalline cubic crystal, the average dislocation contrast factor $\mathbf{C}_{\mathrm{hkl}}$ for the plane (hkl) is given by $[11,12]$ :

$$
\mathrm{C}_{\mathrm{hkl}}=\mathrm{C}_{\mathrm{hoo}}\left(1-\mathrm{qH}^{2}\right)
$$

where

$$
\begin{aligned}
& \mathrm{H}^{2}=\left(\mathrm{h}^{2} \mathrm{k}^{2}+\mathrm{h}^{2} \mathrm{l}^{2}+\mathrm{k}^{2} \mathrm{l}^{2}\right) /\left(\mathrm{h}^{2}+\mathrm{k}^{2}+\mathrm{l}^{2}\right)^{2} \\
& \text { (7) }
\end{aligned}
$$

and $\mathrm{q}$ is a parameter which depends on the elastic constants and type of dislocations.

For screw and edge dislocations, $\mathrm{C}_{\mathrm{hoo}}$ and $\mathrm{q}$ are given by[12]:

$\mathrm{C}_{\text {hoo }}=\mathrm{a}_{1}\left[1-\exp \left(-\mathrm{A}_{\mathrm{i}} / \mathrm{b}_{1}\right)\right]+\mathrm{c}_{1} \mathrm{~A}_{\mathrm{i}}+\mathrm{d}_{1}$

(8)

$\mathrm{q}=\mathrm{a}_{2}\left[1-\exp \left(-\mathrm{A}_{\mathrm{i}} / \mathrm{b}_{2}\right)\right]+\mathrm{c}_{2} \mathrm{~A}_{\mathrm{i}}+\mathrm{d}_{2}$

(9)

The elastic anisotropy constant $\mathrm{A}_{\mathrm{i}}$ is given as [ 12]:

$$
\mathrm{A}_{\mathrm{i}}=2 \mathrm{C}_{44} /\left(\mathrm{C}_{11}-\mathrm{C}_{12}\right)
$$

(10)

where $\mathrm{C}_{11}, \mathrm{C}_{12}$ and $\mathrm{C}_{44}$ are elastic constants. For $\mathrm{PbS}, \mathrm{C}_{11}=124 \mathrm{GPa}, \mathrm{C}_{12}=33 \mathrm{GPa}$ and $\mathrm{C}_{44}=23 \mathrm{GPa}$ [19]. Hence the calculated value of $A_{i}$ is (eq. 12):

$$
\mathrm{A}_{\mathrm{i}}=0.5054
$$

and

$$
\text { (11a) }
$$

$\mathrm{C}_{12} / \mathrm{C}_{44}=1.4347$

(11b)

The values of the parameters $a_{1}, b_{1}, c_{1}, d_{1}$ and $a_{2}, b_{2}, c_{2}, d_{2}$ are independent of $\mathbf{C}_{12} / \mathbf{C}_{44}$ for screw dislocations in fcc crystals but there is a strong dependence of these parameters on $\mathrm{C}_{12} / \mathrm{C}_{44}$ in case of edge dislocations. The value of these parameters for screw dislocations as well as for edge dislocations with $\mathrm{C}_{12} / \mathrm{C}_{44}$ $=0.5,1,2$ and 3 are reported in [12]. The interpolation of these reported values corresponding to $\mathrm{C}_{12} / \mathrm{C}_{44}=$ 1.4347 gives the values of $a_{1}, b_{1}, c_{1}, d_{1}$ and $a_{2}, b_{2}, c_{2}, d_{2}$ for edge dislocation in PbS. The values of these parameters and the calculated values of $\mathrm{C}_{\mathrm{hoo}}$ and $\mathrm{q}$ both for screw and edge dislocations are shown in Table 1. 


\section{Results and discussions:}

The x-ray diffraction profiles of the films are shown in Fig1. Comparisons of the diffraction patterns with the standard X-ray Powder Diffraction data file (ICDD Card No.-5-0592 ) confirms that the films are polycrystalline films of $\mathrm{PbS}$ having fcc structure. The XRD patterns show that all films are well crystallized. The intensity of XRD peaks are seen to be much larger for $0.50 \mathrm{M}$ (LAc) than the corresponding peaks of the other two samples which implies that more number of planes of a particular $\{\mathrm{hkl}\}$ family took part in the process of diffraction at this concentration of $\mathrm{Pb}\left(\mathrm{CH}_{3} \mathrm{COO}\right)_{2}$. Preferred orientation changes from (200) in $0.50 \mathrm{M}(\mathrm{LAc})$ to $(111)$ for $0.75 \mathrm{M}(\mathrm{LAc})$ and $1.00 \mathrm{M}(\mathrm{LAc})$ indicating three dimensional growth of the films at higher concentration of $\mathrm{Pb}\left(\mathrm{CH}_{3} \mathrm{COO}\right)_{2}$. The XRD pattern of $0.75 \mathrm{M}(\mathrm{LAc})$ and $1.00 \mathrm{M}(\mathrm{LAc})$ shows an additional peak (marked as \# in Fig 1) corresponding to the (101) plane of elemental Pb (ICDD card No. 44-0872). It may be due to the imperfections in the ratio of cations to anions due to presence of extra cations in the interstitial sites.

The Nelson-Riley plot of the deposited films are shown in Fig 2. The corrected lattice constants are found to deviate from its bulk value $\left(\mathrm{a}_{0}=5.936 \AA\right)$ [17]. This means that the films are under strain. The strain is found from WH plot of the films (Fig3) .The average crystallite size and the strain as determined from WH plots are listed in Table 2. It is also clear from Fig.3 that there is strong strain anisotropy in the films which necessitates the x-ray line profile analysis of the fims by MWH method.

The Fig 4 is the MWH plot of the films. The values of $\mathbf{C}_{\mathbf{h 0 0}}$ and $\mathbf{q}$ and thereby the average values of $\mathbf{C}_{\text {hkl }}$ (eqs. 8-12) are calculated using various proportions of screw and edge dislocations. The linear plots between $(\boldsymbol{\Delta K})^{2}$ and $\mathbf{K}^{2} \mathbf{C}_{\mathbf{h k l}}$ (using eq.7) for the best fit are shown in the Fig 4. It has been observed that MWH plots give better fitting than WH plot . In all the films, the best MWH fitting is obtained when dislocations are considered to be completely of edge type. The average crystallite sizes are calculated from Scherrer's equation (eq.1), WH equation (eq. 6) and MWH equation(eq.7) while the strain is calculated from WH equation and the dislocation density from MWH equation and these are listed in Table 2. It is observed that the crystallite size decreases as the concentration of $\mathrm{Pb}\left(\mathrm{CH}_{3} \mathrm{COO}\right)_{2}$ increases. At $0.50 \mathrm{M}$, all the released $\mathrm{Pb}^{2+} \mathrm{s}$ react with all available $\mathrm{S}^{2-} \mathrm{s}$ to form large crystallites of $\mathrm{PbS}$ leaving no extra anion or cation in the interstitial sites. With higher concentration of $\mathrm{Pb}\left(\mathrm{CH}_{3} \mathrm{COO}\right)_{2}$, although more $\mathrm{Pb}^{2+} \mathrm{s}$ are released, these, instead of reacting with $\mathrm{S}^{2-\mathrm{s}}$ to form $\mathrm{PbS}$, make themselve present in the interstitial sites giving rise to the XRD peak of elemental $\mathrm{Pb}$. Therefore, the crystallite size decreases at higher molarities. On the other hand, the strain and dislocation density increases with the concentration of $\mathrm{Pb}\left(\mathrm{CH}_{3} \mathrm{COO}\right)_{2}$. The dislocation density is found to be very high $\sim 10^{15}-10^{16}$ $\mathrm{m}^{-2}$. One possible reason for increase of dislocation density with the concentration of $\mathrm{Pb}\left(\mathrm{CH}_{3} \mathrm{COO}\right)_{2}$ is that as molarity of $\mathrm{Pb}\left(\mathrm{CH}_{3} \mathrm{COO}\right)_{2}$ increases, the reaction becomes faster due to availability of more $\mathrm{Pb}^{2+} \mathrm{s}$ and deposition quicker causing increase of dislocation density.

\section{Conclusion:}

Nanocrystalline films of $\mathrm{PbS}$ have been developed in the concentration range of $0.50-1.00 \mathrm{M}$ of $\mathrm{Pb}\left(\mathrm{CH}_{3} \mathrm{COO}\right)_{2}$ by $\mathrm{CBD}$ method. The average crystallite sizes are found to be in the range of 4.99-53.91 nm with very high dislocation density of the order of $10^{15}-10^{16} \mathrm{~m}^{-2}$ and strain in the range of $7.4 \times 10^{-4}-2.82 \times 10^{-3}$. The dislocations are observed to be of edge type. The crystallite sizes, strain and dislocation density are found to be affected by the concentration of $\mathrm{Pb}\left(\mathrm{CH}_{3} \mathrm{COO}\right)_{2 . .}$ Pure film of $\mathrm{PbS}$ with very high degree of crystallinity is found at $0.50 \mathrm{M}$. At $0.75 \mathrm{M}$ and $1.00 \mathrm{M}$, presence of elemental $\mathrm{Pb}$ is detected.

The advantage of the method used in this paper for structural analysis is that it separates the contribution of crystallite size and strain to the $\mathrm{X}$-ray line broadening and determines the dislocation density alongwith crystallite size and strain.

\section{Acknowledgement:}

The authors are grateful to the Material Science Division of the North East Institute of Science and Technology, Jorhat, Assam, India for providing XRD facility. This article has been inspired by the work of MPC Kalita and his team [MPC Kalita et al, Materials Letters 87 (2012), 84-86]

\section{Tables}

Table 1: Choo, $q$ and parameters of eqs.(10) and (11) for screw and edge dislocations in $\mathrm{PbS}$

\begin{tabular}{|l|l|l|l|l|l|l|l|l|l|l|l|l|}
\hline $\begin{array}{l}\text { Type of } \\
\text { Dislocation }\end{array}$ & $\mathbf{C}_{\mathbf{1 2}} / \mathbf{C}_{\mathbf{4 4}}$ & $\mathbf{A}_{\mathbf{i}}$ & $\mathbf{a}_{\mathbf{1}}$ & $\mathbf{b}_{\mathbf{1}}$ & $\mathbf{c}_{\mathbf{1}}$ & $\mathbf{d}_{\mathbf{1}}$ & $\mathbf{a}_{\mathbf{2}}$ & $\mathbf{b}_{\mathbf{2}}$ & $\mathbf{c}_{\mathbf{2}}$ & $\mathbf{d}_{\mathbf{2}}$ & $\mathbf{C}_{\text {hoo }}$ & $\mathbf{q}$ \\
\hline Screw & 1.4347 & 0.5054 & 0.174 & 1.9522 & 0.0293 & 0.0662 & 5.4252 & 0.7196 & 0.069 & -3.197 & 0.1207 & -0.4243 \\
\hline Edge & & & 0.2048 & 2.3346 & 0.0183 & 0.0882 & 5.3707 & 0.8446 & 0.085 & -3.8629 & 0.1373 & -1.4011 \\
\hline
\end{tabular}


Table 2: Lattice Constant, Average Crystallite Size, Strain and Dislocation Density

\begin{tabular}{|c|c|c|c|c|c|c|c|}
\hline \multirow{2}{*}{$\begin{array}{l}\text { Name of the } \\
\text { sample }\end{array}$} & \multirow{2}{*}{$\begin{array}{l}\text { Corrected } \\
\text { Lattice } \\
\text { Constant }(\AA)\end{array}$} & \multirow{2}{*}{$\begin{array}{l}\text { Proportions of } \\
\text { Dislocations } \\
\text { for best MWH } \\
\text { fit }\end{array}$} & \multicolumn{3}{|c|}{ Average Crystallite Size (nm) from } & \multirow{2}{*}{$\begin{array}{l}\text { Strain from } \\
\text { WH plot }(\mathbf{x 1 0} \\
\left.3^{3}\right)\end{array}$} & \multirow{2}{*}{$\begin{array}{l}\text { Dislocation } \\
\text { Density }\left(\mathbf{m}^{-2}\right)\end{array}$} \\
\hline & & & $\begin{array}{l}\text { Scherrer's } \\
\text { formula }\end{array}$ & WH plot & MWH plot & & \\
\hline $0.50 \mathrm{M}(\mathrm{LAc})$ & 5.939 & $100 \% \mathrm{E}^{*}$ & 53.67 & 54.54 & 53.91 & 0.74 & $2.58 \times 10^{15}$ \\
\hline $1.00 \mathrm{M}(\mathrm{LAc})$ & 5.913 & $100 \% \mathrm{E}^{*}$ & 5.30 & 5.31 & 4.99 & 2.82 & $5.85 \times 10^{16}$ \\
\hline
\end{tabular}

* E- Edge Dislocation

\section{Figures}
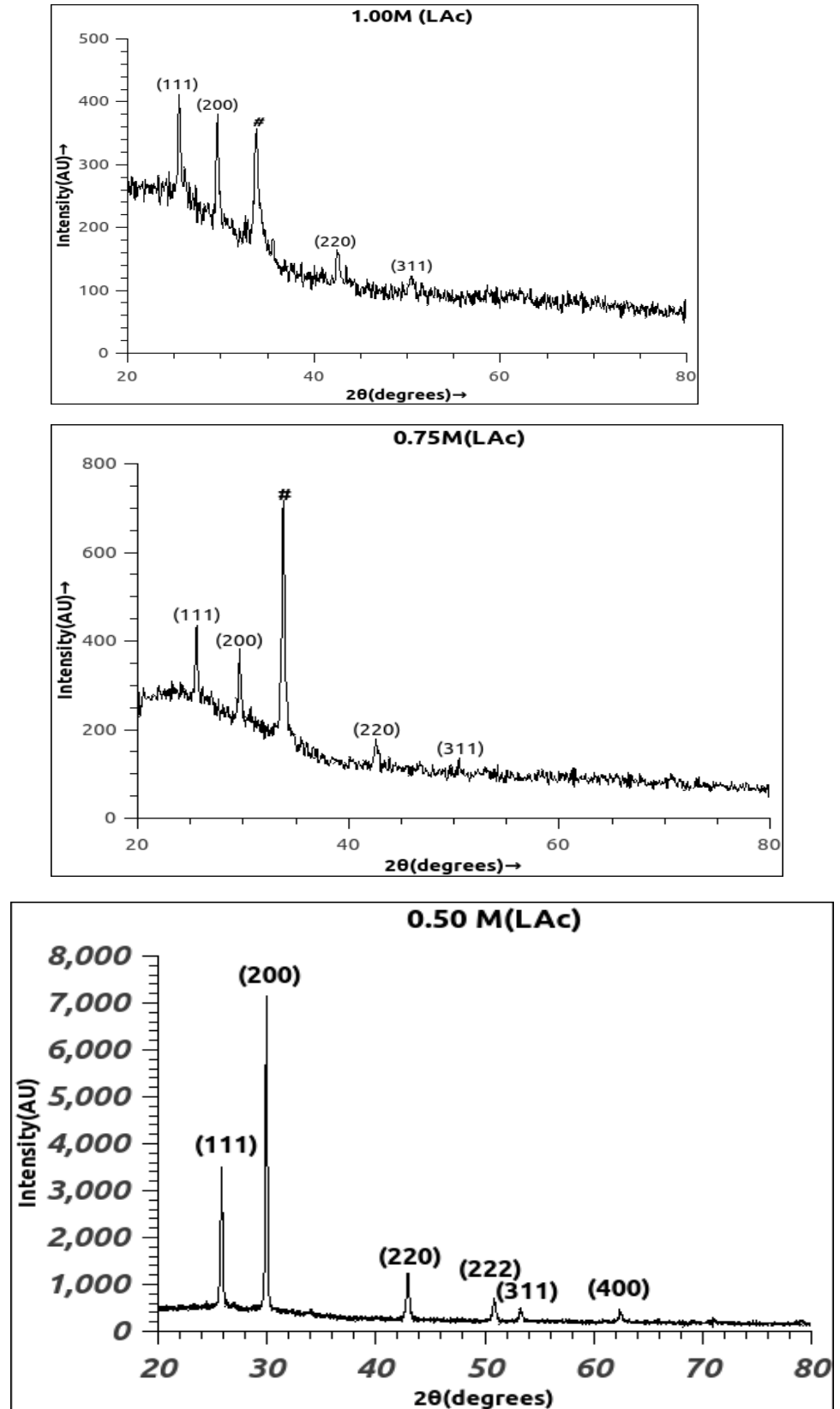

Fig 1: XRD pattern of the deposited Films 0.50M (LAc), 0.75M (LAc) and 1.00M (LAc) 


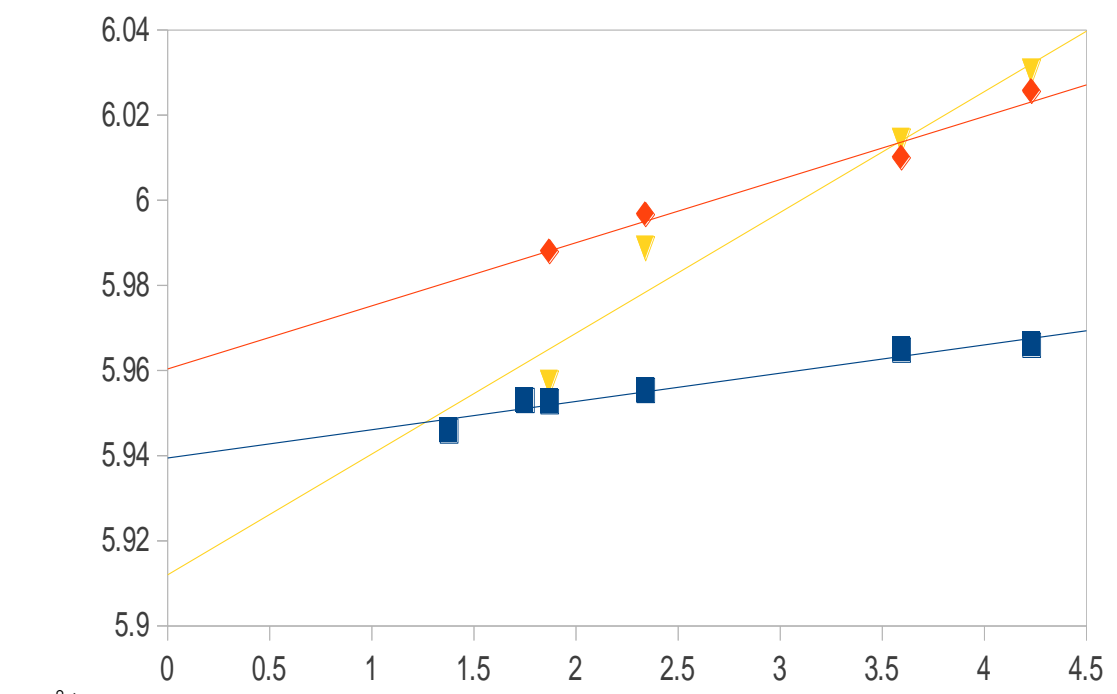

$0.50 \mathrm{M}(\mathrm{LAc})$

$0.75 \mathrm{M}(\mathrm{LAc})$

$\mathrm{a}(\AA)$

$f(\theta)$

Fig 2: Nelson-Riley plots of the deposited film
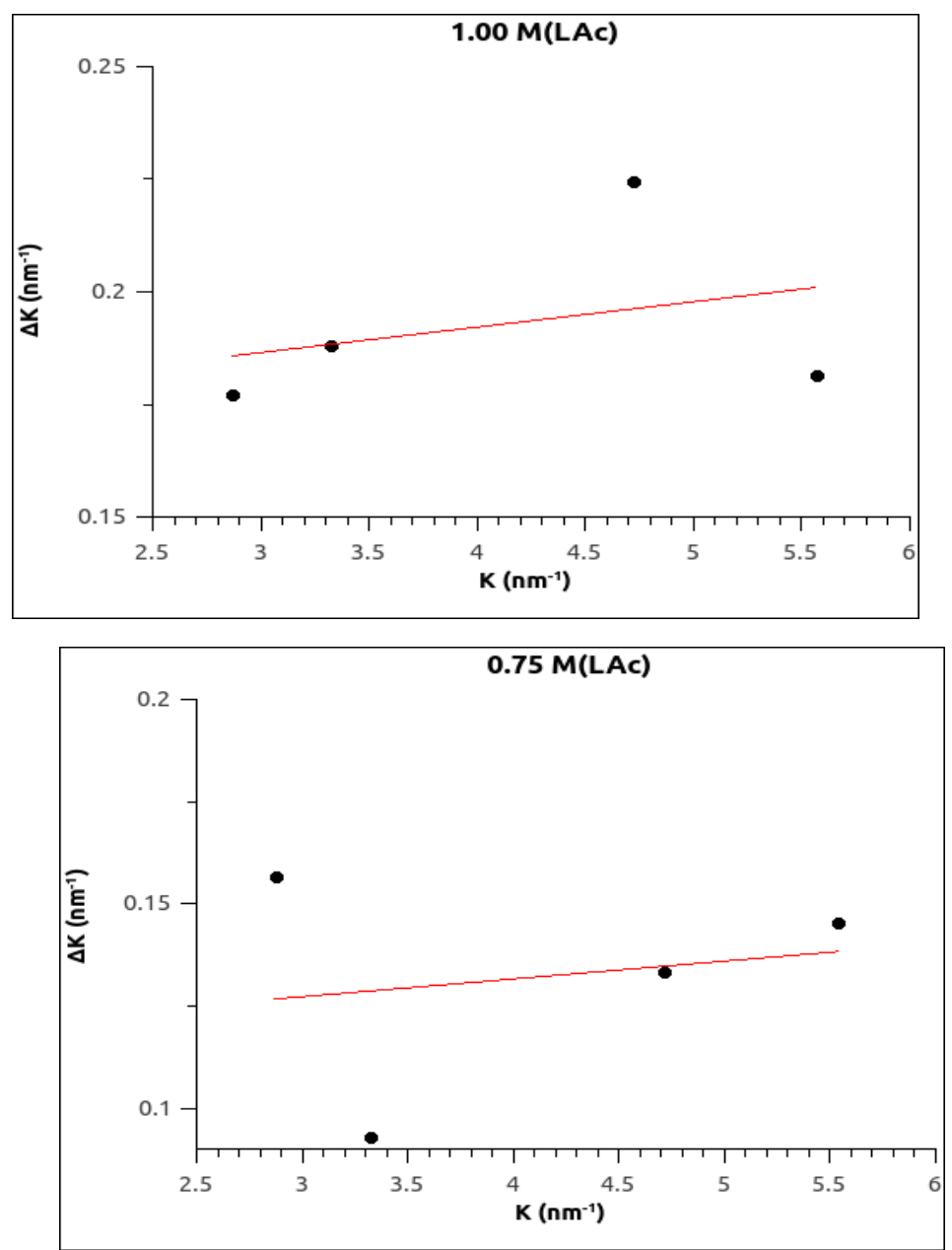


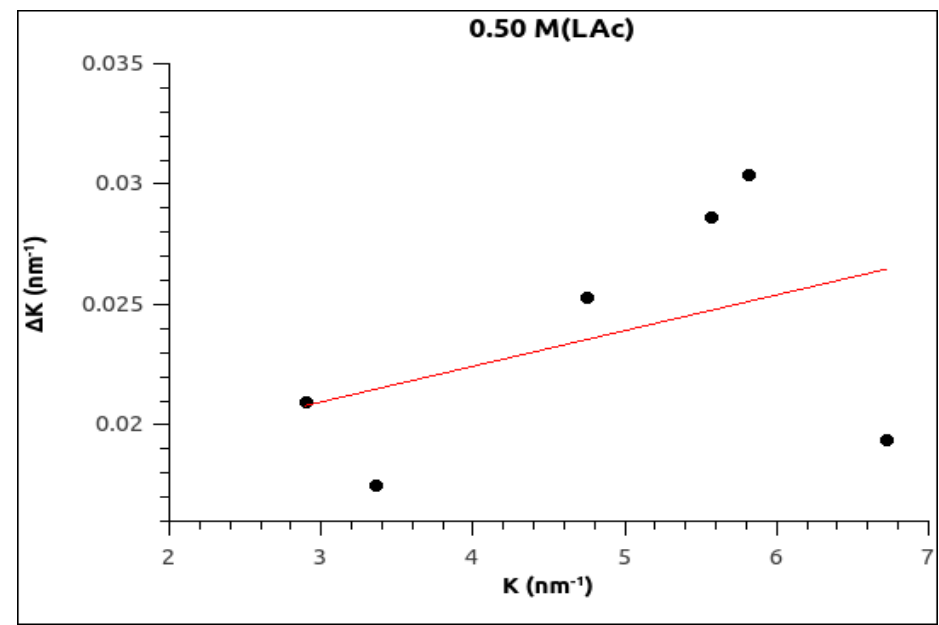

Fig 3 : WH plot of the deposited films $0.50 M(L A c), 0.75 M(L A c)$ and 1.00M(LAc)
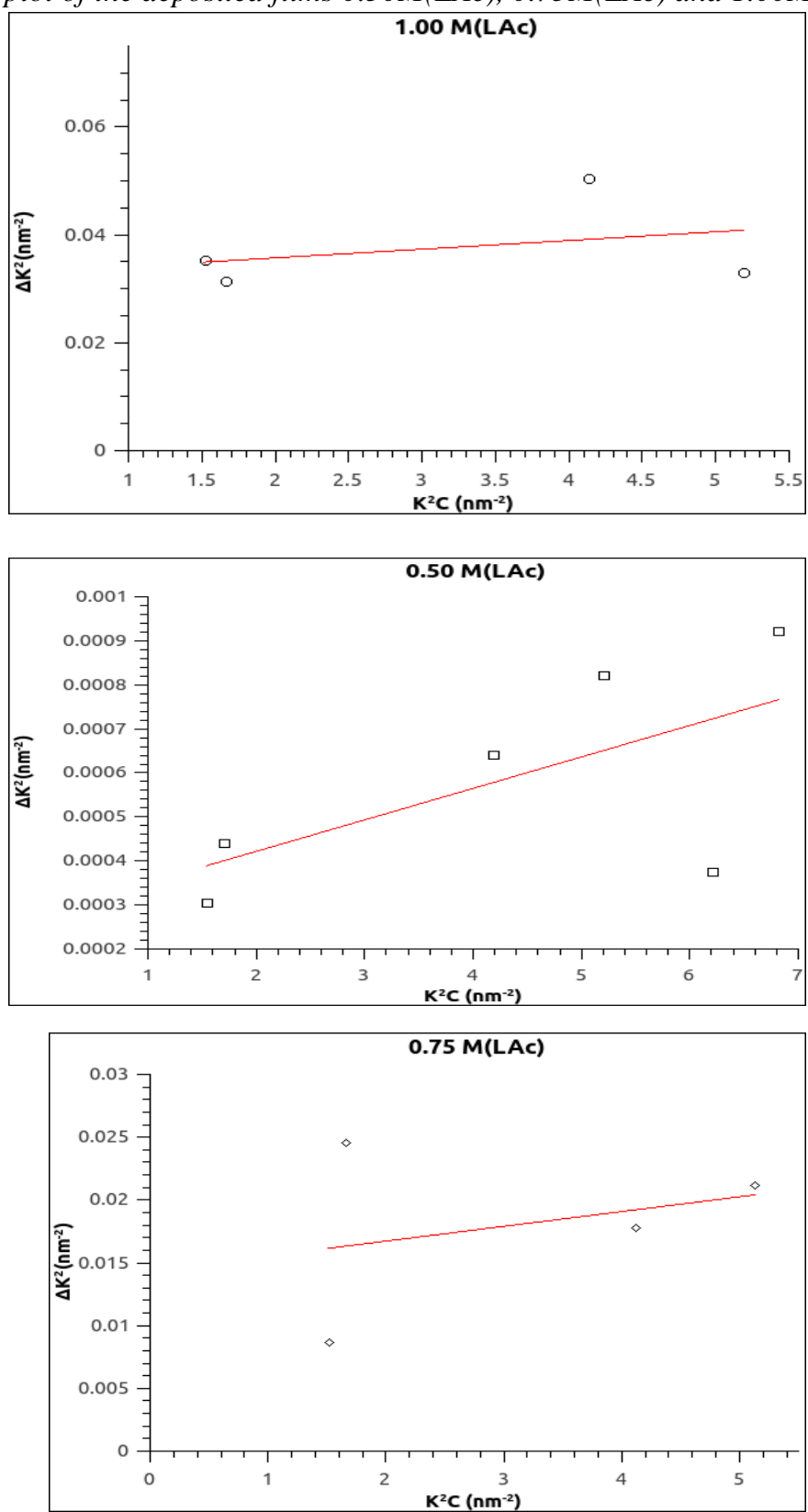

Fig 4 : MWH plot of the deposited films 0.50M(LAc), 0.75M(LAc) and 1.00M(LAc) 


\section{References}

[1] I Ka, D Ma, M A El Khakani, J Nanopart Res 13(2011), 2269-2274

[2] T. L. Remadevi, K. C. Preetha, J Mater Sci: Mater Electron 23(2012), 2017-2023

[3] P.K. Nair, V.M. Garcia, A.B. Hernandez, M.T.S. Nair, J. Appl. Phys. 24(1991), 1466-1472

[4] M. A. Barote, A. A. Yadav T. V. Chavan E. U. Masumdar, Digest Journal of Nanomaterials and Biostructures, 6(2011), 979 - 990

[5] S. Kaci, A. Keffous, M. Trari, H. Menari, A. Manseri, B. Mahmoudi, L. Guerbous, Optics Communications, 283 (2010), 33553360

[6] R Devi, P Purkayastha, P K Kalita, B K Sarma, Bull. Mater. Sci., 30(2007), 123-128

[7] S. Kaci, A. Keffous, M. Trari, O. Fellahi, H. Menari, A. Manseri, L. Guerbous, Journal of Luminescence, 130 (2010), 1849-1856

[8] M.M. Abbas, A. Ab-M. Shehab, N-A. Hassan, A-K. Al-Samuraee, Thin Solid Films, 519 (2011), 4917-4922

[9] Diwaker Kumar, Garima Agarwal, Balram Tripathi, Devendra Vyas, Vaibhav Kulshrestha, Journal of Alloys and Compounds, 484 (2009), 463-466

[10] N. Choudhury, B.K. Sarma,Thin Solid Films, 519 (2011), 2132-2134

[11] T Ungar, G Tichy. Phys Status Solidi A, 171(1999), 425-434

[12] T Ungar, I Dragomir, A Revesz, A Borbely, J Appl Crystallography, 32(1999), 992-1002

[13] A Revesz, T Ungar, A Borbely, J Lendvai, Nanostruct Mater 7(1996), 779-788

[14] Michael B Kerber, Erhard Schafler, Michael J. Zehetbauer, Rev.Adv.Mater.Sci.10(2005), 427-433

[15] Yu Jun Yang, Shengshui Hu, Thin Solid Films 516 (2008), 6048 - 6051

[16] J B Nelson, D P Riley, Proc. Phys. Soc. (London) 57(1945), 160

[17] N Choudhury, B K Sarma, Bull. Mater. Sci., 32(2009), 43-47

[18] G.K. Williamson, W.H. Hall; Acta. Metall. 1(1953), 22

[19] S Abe, K Masumoto, J Cryst Growth, 217(2000), 25-30 